\title{
Recycling Paper Products: Some Implications for Environmental Policy
}

$\mathrm{W}$ e live in a throw-away society, and much of what we throw away is paper: in Western Europe, paper comprises about $35 \%$ of household waste by volume. But a recent study by the Undersigned, Leader of IIASA's Forest Resources Project, and Vrjö Virtanen, indicates that attempts to solve the problem by just recycling this mountain of paper may cause more harm than good to the environment.

With the rise of environmentalism, closed-loop recycling has become extremely popular. Pushed by anxious citizens, many governments have adopted policies to encourage large-scale recycling in the belief that it will lower consumption of resources and energy, reduce production costs, and reduce overall stress on the environment.

Recycling paper products has some obvious environmental and economic benefits. For example, it limits the growth of rubbish-dumps and reduces demand in other activities related to the paper-product cycle - making new paper from waste paper products requires less total energy than using new wood-fibres.

\section{Beware that Recycling does not Increase Consumption}

It is less obvious that large-scale recycling may actually increase the consumption of non-renewable resources. 'For any country in Europe, recycling of paper clearly has advantages, but only up to a point,' our Study claims: 'If we were to recycle all of our paper products, the net effect would be to increase air pollution and consumption of fossil fuels.' Preliminary analyses indicate that airborne emissions of $\mathrm{SO}_{2}$ and $\mathrm{NO}_{\mathrm{x}}$, and net emissions of $\mathrm{CO}_{2}$, would all increase, as would net emissions of solid waste.

From our study we may add that recycling could also indirectly damage Europe's forests. The increase of pollutants would worsen air pollution in Europe - $\mathrm{SO}_{2}$ and $\mathrm{NO}_{\mathrm{x}}$, together with $\mathrm{O}_{3}$, are believed to be the main factors causing the decline of Europe's forests. Large-scale recycling would also reduce the demand for new woodfibres, giving commercial woodland owners less incentive to tend their forests. For many of Europe's forests, this would be disastrous. If they are not properly managed, stands of trees become more susceptible to attack by insects, diseases, air pollutants, and fire.

In other words, our study indicates that, large-scale recycling of paper - a measure adopted to save trees and help the environment - could instead end up damaging forests and increasing production of environmentally harmful waste. This underscores the great complexity of the recycling debate, and the need for further studies. We should accordingly point out that the objective of an efficient materials production and recycling scheme should not be recycling per se, but rather the minimum use of resources and the reduction of pollutants associated with all aspects of the 'life-cycle' of a product. Advantages gained in one area might easily be lost in another. Analysis of the product's entire life-cycle - what scientists call a "cradleto-grave' analysis - gives a more complete picture of environmental gains and losses.

Nilsson \& Virtanen carried out a preliminary study of paper-products' recycling in Western Europe, using the IDEA life-cycle model developed at IIASA. The objectives of the study were to evaluate the use of a life-cycle approach to paper recycling, to gain insights into the problem of introducing large-scale recycling into existing

TABLE I

Trends with Increased Recycling of Paper, based on Conditions Prevailing at the End of the 1980s.

\section{Energy Consumption}

Electric power

Heat and steam

Fossil fuels

Non-renewable primary energy sources

Renewable primary energy sources

Emissions - Air

$\mathrm{SO}_{2}$

$\mathrm{NO}_{\mathrm{x}}$

$\mathrm{CH}_{4}$

Gross $\mathrm{CO}_{2}$

$\mathrm{CO}$

Net $\mathrm{CO}_{2}$

Decreased

Decreased

Increased

Increased

Decreased

Increased

Increased

Decreased

Decreased

Decreased

Increased (or

decreased fixation)

\section{Emissions - Water}

TSS $=$ Total Suspended Solids

BOD $=$ Biological Oxygen Demand

$\mathrm{COD}=$ Chemical Oxygen Demand

$\mathrm{AOX}=$ Chlorinated Organic Compounds

\section{Increased}

Increased

Decreased

Decreased

\section{Materials}

Raw materials for pulp and paper production Decreased (other than wood)

Wood consumption

Decreased

Waste Production

Gross solid waste

Net solid waste

Decreased

Increased

\section{Forest Management}

Forest vitality

Decreased

production and distribution systems, and to broaden the scope of the public debate over environmental policy. Based on conditions prevailing in the late $1980 \mathrm{~s}$, three different scenarios were selected:

- maximum recycling,

- selective recycling, and

- no recycling; here it was assumed that wastepaper was burned in central plants to provide energy.

The scenarios were not intended to represent realistic future recycling strategies, but instead to demonstrate the environmental impact of different strategies. The intention was to find trends, not details. The results clearly show that the task of identifying the best material-production and recycling schemes, from an environmental point of view, is much more complex than the current debate would suggest.

\section{Forest Utilization Still Widely Below Optimum}

The maximum recycling scenario shows forest utilization far below the level to be sustainable for Western Europe: not enough trees are cut to keep the remaining trees healthy! The results also indicate that a balanced mixture of recycling and energy recovery might be the best solution. Recycling minimizes the use of some resources and reduces emissions, while energy recovery reduces the use of fossil fuels. The appropriate balance, however, would almost certainly vary widely from country to country and region to region. 
The point of the feasibility study was not to find the ultimate solution of the wastepaper problem, but to get an overview of the environmental impact of large-scale recycling of paper products. It shows clearly that simply recycling as much as we can is not the answer to our environmental problems. Before we commit ourselves to large-scale programmes for recycling of paper products, we need to do more research into the links between recycling, energy consumption, gaseous emissions, and other associated environmental effects. These interrelationships are complex, and they are not always obvious.

Although our study was limited to the recycling of paper products in Western Europe, the findings raise questions about the wisdom of a blind commitment to full recycling of any product or material: in the search for environmental sustainability, recycling is an important tool, but it is not a cure-all. Table I indicates trends with increased recycling of paper. A book elaborating on the results of this study, to be entitled Environmental Impacts of Waste Paper Recycling: A Feasibility Study, will be published by Earthscan Publications Ltd, London, England, UK in the spring of 1993.

STEN NILSSON, Leader
Forestry and Climate Change Project
International Institute for Applied Systems
Analysis (IIASA)
A-2361 Laxenburg
Austria.

\section{Trapnell Fund for Environmental Field Research in Africa}

$\mathrm{T}$ he University of Oxford invites applications for support for field-based research concerned with the African environment, with reference to all or any of the following aspects of non-managed ecosystems:

(a) Local climatic variation and geomorphology;

(b) Pedology, soil biology, and soil conservation;

(c) The history, composition, and successional phases, of the vegetation, and the conservation of indigenous forests; and

(d) The carrying capacity of land for human populations.

All other considerations being equal, preference may be given to proposals involving observational and empirical field research into the ecological aspects either of soils or of indigenous forests and woodlands, in the tropical region, and, in the case of studies of the carrying capacity of land, to proposals examining the ecology and current carrying capacity for pastoral and subsistence land-use.

Grants will be awarded either for field research in Africa, or for research in Oxford based upon field-work or previous field-based recording in Africa. Awards at present will normally be of up to approximately $£ 5,000$ in value. Applications for matching funds would be particularly welcome, i.e. where partial support for a project or studentship has already been obtained from some other source or sources.
Applicants must be graduates of British or African universities and must either be working for a research degree of the University of Oxford, or hold a postdoctoral position at the University. Applications should consist of a curriculum vitae, evidence of graduation, a summary of the research proposal not exceeding 4 sides of A4 paper in length, a full breakdown of the cost involved with details of the amount sought and, if appropriate, of other support obtained, and the names and addresses of two academic referees. Those seeking support for a project on the basis of which they hope to be accepted to read for a research degree at Oxford, should note that they must apply separately for admission in the usual way. They should also note that the awards are unlikely to cover the costs of fees or to provide a maintenance grant.

Applications and queries about the scheme should be addressed to the undersigned Dr P.R. Gambles. There is no application form, but please note that the closing date for receipt of applications is 1 MARCH 1993.

\section{Peter R. Gambles University Offices Wellington Square Oxford OXI $2 J D$ England, UK.}

\section{Symposium Marking Opening of IUCN's New Building*}

T his Symposium underlined a message from its latest General Assembly, namely that IUCN should play a greater role than hitherto in advocacy — not just in devising and trying out good policies but by arguing their case in the corridors of power. Thus IUCN should take the role of 'influencing individual and public decision-making' into its mission. Also, there must be improved integration between the various parts of IUCN's programmes; inter-sectoral coordination will be particularly important in such tasks as advising on the implementation of the UN Convention on Biodiversity.

In developing its programme, IUCN must mobilize its membership more effectively and make sure that members are involved as partners in IUCN work wherever possible. The Union must continue the shift from successful field projects to (a) policy analysis and provision of policy tools, (b) institution-building, and (c) provision of specialist services.

The system of governance of IUCN should be reviewed, it having been suggested that the General Assembly is no longer sufficient as a forum for debating and defining policy but may well need to be buttressed by regional assemblies. The Council also needs reviewing, with Regional Councillors keeping in touch with the membership they represent, and funds being provided where necessary to ensure this. National and Regional Committees would be one possible way of achieving such links.

While IUCN must treat governmental and NGO members even-handedly, stronger partnerships should be built with the NGO membership, and more global partnerships be embraced and invigorated. Whether the Union can develop an effective link with the UN Commission for Sustainable Development will depend on the precise form in which the Commission is constituted, and the extent to which the effectiveness of ECOSOC, its parent body, is increased. For IUCN's involvement to be worth-while, there must be an opportunity for real partnership.

The Ecosystem Conservation Group, as an informal discussion group of the UN agencies concerned with sustainable development and environmental conservation and involving major environmental bodies such as IUCN, WWF, and WRI, has great potential value, but needs to be made more effective. It could be used to discuss the scope for joint action, for example in shared topics such as 